\title{
Overall satisfaction increased more with inhaled insulin than with subcutaneous insulin in type 1 diabetes
}

\author{
Gerber RA, Cappelleri JC, Kourides IA, et al. Treatment satisfaction with inhaled insulin in patients with type 1 diabetes. A \\ randomized controlled trial. Diabetes Care 2001 Sep;24:1556-9.
}

\section{QUESTION: In patients with type 1 diabetes mellitus, is patient satisfaction greater with inhaled insulin use than with subcutaneous insulin injection?}

Source of funding:

Pfizer Inc.

For correspondence: $\mathrm{Dr}$ $R$ A Gerber, Pfizer Inc, Groton, CT,USA. robert_a_gerber@ groton.pfizer.com.

Design

Randomised \{allocation concealed $*$ \} trolled trial with 12 weeks of follow up.

\section{Setting}

10 centres in the US.

Inhaled v subcutaneous insulin in type 1 diabetes at 12 weeksई

\begin{tabular}{|c|c|c|c|}
\hline \multirow[b]{2}{*}{ Outcomes } & \multicolumn{2}{|c|}{$\begin{array}{l}\text { Mean percentage increase from } \\
\text { baseline }\end{array}$} & \multirow{2}{*}{$\begin{array}{l}\text { Difference } \\
(95 \% \mathrm{CI})\end{array}$} \\
\hline & Inhaled & Subcutaneous & \\
\hline Overall satisfaction & $35 \%$ & $11 \%$ & $25 \%(6.6$ to 43$)$ \\
\hline Convenience or ease of use & $41 \%$ & $11 \%$ & $30 \%(11$ to 50$)$ \\
\hline Social comfort & $28 \%$ & $18 \%$ & $10 \%$ \ $(-15$ to 35$)$ \\
\hline
\end{tabular}

§Outcomes measured with Patient Satisfaction with Insulin Therapy Questionnaire; higher score = greater satisfaction.

ๆCalculated from data in article.

\section{COMMENTARY}

The core finding in the study by Gerber $e t$ al was a greater improvement in overall satisfaction among patients receiving inhaled plus 1 subcutaneous injection of insulin than among those continuing 2 or 3 daily injections of insulin. Details of the insulin regimens are sparse, but patients received a mixture of short acting and medium acting conventional insulins. Whether these were pre-mixed preparations or how they were administered is not clear. These questions are not trivial because many patients with type 1 diabetes find it inconvenient to draw up 2 different insulins into the same syringe. Moreover, once a medium acting preparation is injected at breakfast, the patient is committed to consuming a meal several hours later. Current advice is that conventional, short acting insulins should be given 20 to 30 minutes before eating. Finally, many patients report that insulin pens and their needles are much more portable and less painful than disposable syringes.

Comparing inhaled insulin that is given immediately before meals and uses a new technology (a new treatment that interested patients enough to enrol in a study) with a less convenient regimen was likely to result in greater satisfaction. What is surprising is the almost $11 \%$ overall increase in satisfaction in those continuing subcutaneous injections. However, this study was not large enough to show differences in social comfort in users of the bulky insulin inhaler, but the beneficial trend is consistent with a previous study. ${ }^{1}$

Other problems exist with inhaled insulin. In dose equivalence terms, 10 times more insulin needs to be given before meals with the inhaler than with injection. Short term respiratory function reported in this study did not change, and preliminary data suggest no detectable problems at 24 months. ${ }^{2}$ However, longer term surveillance is essential.

To appropriately test the hypothesis that inhaled insulin is more acceptable to patients, a crossover trial comparing it with multiple injection treatment using fast acting analogues in patients with good glycaemic control (perhaps $<8 \%$ glycated haemoglobin value) needs to be done.

Rudy Bilous, MD

James Cook University Hospital, Middlesbrough, UK

1 Cappelleri JC, Gerber RA, Rosenstock J, et al. Relationship between improved patient satisfaction and improved glycemic controls in patients with type 1 and type 2 diabetes mellitus treated with inhaled insulin: pooled results from two multicenter randomized controlled trials. Diabetes 2001;50(suppl 2):A108.

2 Cefalu WT. Inhaled insulin: a proof-of-concept study [letter]. Ann Intern Med 2001;134:795

\section{Patients}

$\{72$ patients $\} \ddagger$ who were 18 to 55 years of age and were following a stable insulin administration schedule of 2 to 3 daily injections for $\geqslant 2$ months. Other inclusion criteria were screening and pre-randomisation glycated haemoglobin values between $7.0 \%$ and $11.9 \%$, fasting plasma C peptide concentration $\leqslant 0.2 \mathrm{pmol} / \mathrm{ml}$, body weight $80 \%$ to $130 \%$ of ideal, non-smoking for $\geqslant 6$ months, normal results on chest $\mathrm{x}$ ray and pulmonary function tests, and normal sinus rhythm (rate 50 to 100 beats/min). 69 patients (96\%) (mean age 37 y, 54\% men, $80 \%$ white) were considered for analysis.

\section{Intervention}

35 patients were allocated to receive preprandial inhaled insulin immediately before meals using a dry powder aerosol delivery system and subcutaneous ultralente insulin at bedtime. 37 patients were allocated to receive subcutaneous insulin (control group) 2 or 3 times/day according to each patient's usual split or mixed insulin regimen.

\section{Main outcome measures}

A self administered questionnaire (Patient Satisfaction with Insulin Therapy) developed by Pfizer Inc was used to measure overall satisfaction (score range 15 to 75 ), convenience or ease of use (score range 10 to 50), and social comfort (score range 5 to 25).

\section{Main results}

\{Analysis was by intention to treat\} $\}$. Patients who completed all items in the overall scale or in each subscale of the questionnaire at baseline and at 12 weeks were included in the analysis (range 92\% to 94\%). At 12 weeks, patients in the inhaled insulin group had greater increases in overall satisfaction and convenience or ease of use scores than did those in the subcutaneous insulin group (table). Groups did not differ for increase in social comfort (table).

\section{Conclusion}

In patients with type 1 diabetes mellitus, increases in overall satisfaction and convenience or ease of use were greater with inhaled insulin than with subcutaneous insulin injection, but groups did not differ for increase in social comfort.

*See glossary.

†Information provided by author.

\$Skyler JS, Cefalu WT, Kourides IA, et al. Lancet 2001;357:331-5. 